\title{
Treatment Outcome with Implant-supported Mandibular Overdenture opposing Natural Dentition
}

\author{
${ }^{1}$ Sushil Kar, ${ }^{2}$ Arvind Tripathi
}

\begin{abstract}
Although the conventional complete denture has been a standard treatment option for edentulous patients, it may not thoroughly fulfill the esthetic or functional needs of many denture wearers. This situation is commonly encountered, especially in relation to the mandibular ridge. Over the last decade, implant-supported overdenture has emerged as a successful alternative to the more commonly used removable prosthesis. The article discusses the fabrication procedure of an implant-assisted overdenture.
\end{abstract}

Keywords: Conventional, Implant, Maxillomandibular, Overdenture, Prosthesis.

How to cite this article: Kar S, Tripathi A. Treatment Outcome with Implant-supported Mandibular Overdenture opposing Natural Dentition. Int J Clin Dent Res 2017;1(1):45-48.

Source of support: Nil

Conflict of interest: None

\section{INTRODUCTION}

The primary reason individuals seek prosthodontic treatment is to restore their psychological well-being and quality of life, other than replacement of missing teeth and soft tissues. ${ }^{1}$ Although conventional complete dentures have been a routine treatment option for edentulous patients, better alternatives are now available. ${ }^{2}$ The conventional denture wearers may not be thoroughly satisfied with the removable prosthesis, either functionally or esthetically, thus opting for better alternative restorative options. ${ }^{3}$ The rate of clinical success and patient acceptance of implant-based denture is better. ${ }^{4}$

The use of Implant-retained overdenture has successfully eliminated many of the shortcomings associated with conventional dentures. ${ }^{5}$ Over the years, it has been experienced that the suboptimal retention of the mandibular prosthesis is the main reason behind patient dissatisfaction. It has been well established that the placement

\footnotetext{
${ }^{1}$ Professor, ${ }^{2}$ Professor and Head

1,2Department of Prosthodontics, Saraswati Dental College and Hospital, Lucknow, Uttar Pradesh, India

Corresponding Author: Sushil Kar, Professor, Department of Prosthodontics, Saraswati Dental College and Hospital Lucknow, Uttar Pradesh, India, Phone: +91052267876, e-mail: drsushil_kar@yahoo.co.in
}

of an implant under a complete denture framework enhances retention, stability, facial harmony, as well as an improved occlusal efficiency. ${ }^{6}$ In the present case series, two patients with a history of hemimaxillectomy over a period of 5 years were rehabilitated in the form of obturator prosthesis.

\section{CASE REPORT}

A 70-year-old male patient was referred to the Department of Prosthodontics at Saraswati Dental College, Lucknow, India, with the primary complaint of an illfitting mandibular denture and diminished ability to eat or swallow without discomfort. Extraoral examination revealed that the jaw relationship was slightly prognathic in accordance with Angle's classification. Facial support, especially in the lower third portion, was esthetically unsatisfactory (Fig. 1).

Intraorally, the maxillary arch had complete set of teeth. The mandibular ridge was completely edentulous, covered by firm, healthy oral mucosa. The oral hygiene of the patient was acceptable. Thorough assessment of the edentulous ridge was done to ascertain the number and position of the endosseous implants. The crucial factors kept in mind while formulating the treatment plan and selecting the type of attachment included costeffectiveness, degree of retention required, height and

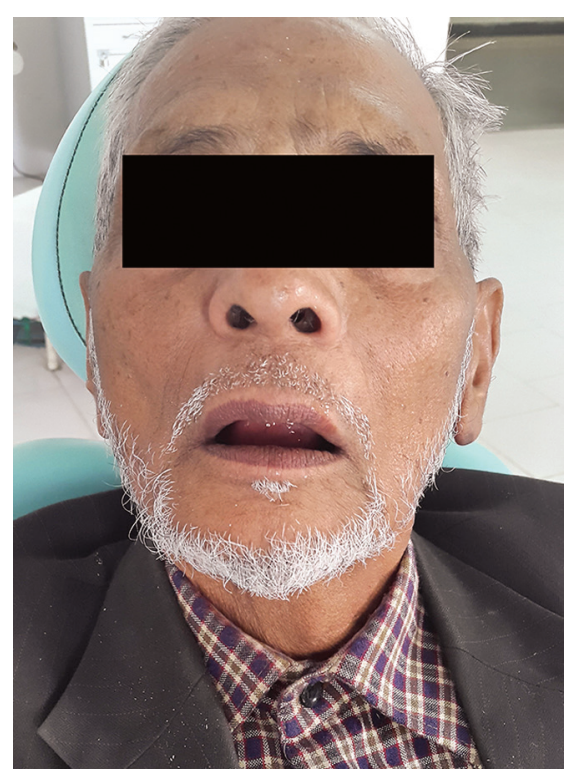

Fig. 1: Preoperative extraoral view 


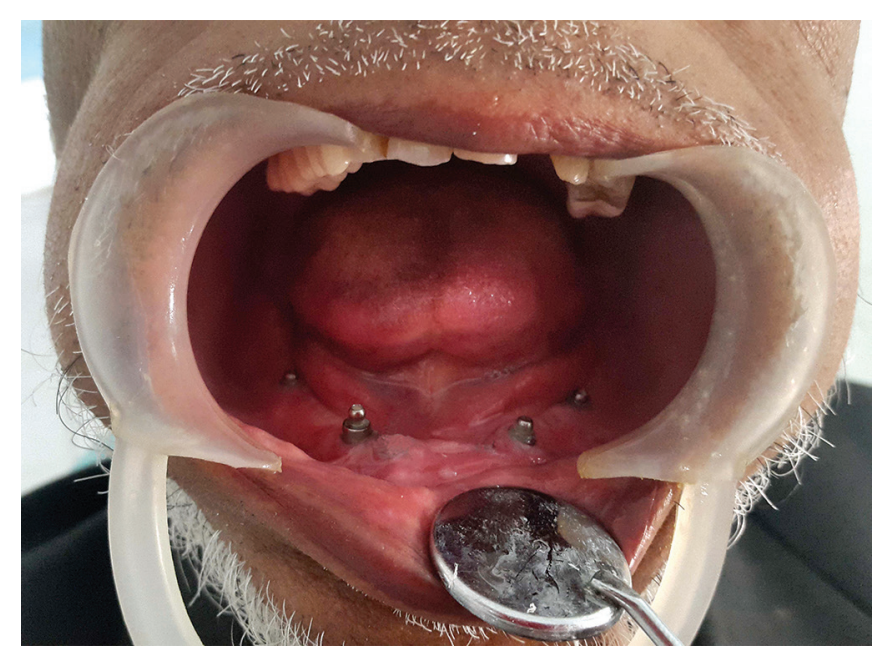

Fig. 2: 3 Months implants after surgery

width of the bone available for placement of implants, the socioeconomic status of the patient, the condition of the hard and soft tissues of the antagonistic ridge, as well as the maxillomandibular relationship. ${ }^{7}$

Radiographic evaluation was done to get a detailed picture of the quality and quantity of the residual bone. The proposed treatment outline consisted of surgical placement of four implants in the mandibular arch, followed by fabrication of an implant-retained overdenture. On discussion, the patient agreed with the treatment plan.

After radiographic evaluation, the mandibular canine and premolar regions on either side of the midline were considered appropriate for implant placement in relation to the available bone height and width. Prior to implant placement, the patient did not receive any bone graft for improving the anatomy of the planned site of implantation.

In stage I surgery, a full-thickness mucoperiosteal flap was raised and a total of four dental implants were placed in the planned positions using an appropriate surgical stent. ${ }^{8}$ The flap was sutured and patient was recalled after 7 days for removal of sutures. A comprehensive antibiotic coverage, analgesics, and chlorhexidine mouthwash were followed by the patient. Stage II of the surgical procedure was done 3 months after the primary implant surgery. The purpose of this surgery was to attach healing abutments to the implants in order to facilitate unhampered soft tissue healing. ${ }^{9}$

The healing abutments from the implants were removed. The ball abutments were inserted into the implants to check for proper fit (Fig. 2). Once ensured for a good fit, the ball abutments were removed and the impression copings on the implants were seated and tightened with the screws. At this stage, irreversible hydrocolloid impressions were taken for both arches. This was followed by fabrication of maxillary and mandibular individual

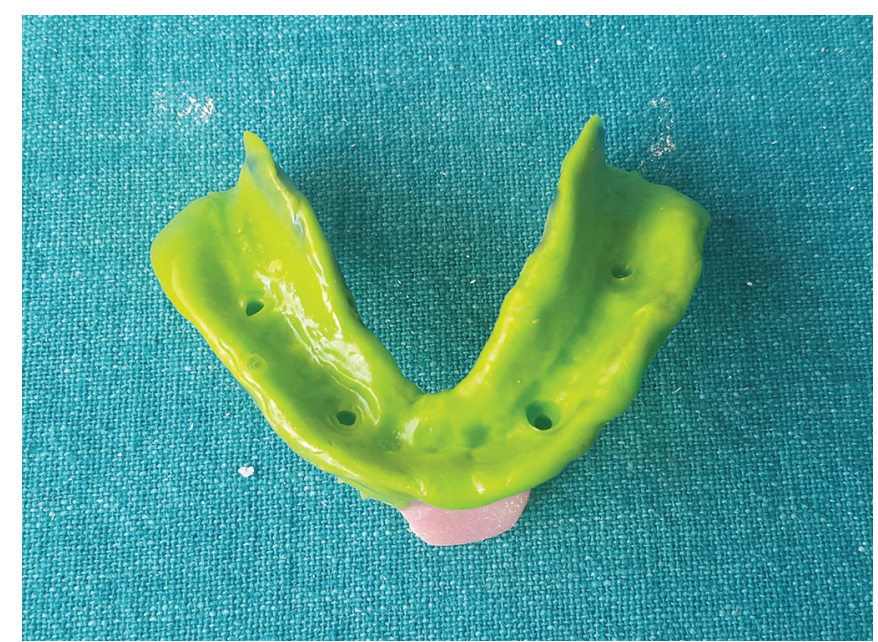

Fig. 3: Final polyvinyl siloxane impression

trays using autopolymerizing resin. The borders of the customized trays were refined with low-fusing impression compound softened in a water bath. Final impressions were obtained with light body polyvinyl siloxane impression material (Fig. 3). After the impression set, the impression copings were removed and replaced with the healing abutments. The implant analogs were attached to the impression copings and carefully replaced back into the impression. Master casts were poured with dental stone to fabricate the record bases and occlusal rims. Using the Core tool, the locator abutments were tightened into the same implants indicated on the master cast (Fig. 4).

In the subsequent visit, the maxillomandibular jaw relation was recorded. Lip support and phonetics were reevaluated at the try-in stage, following which the dentures were processed with heat cure polymerizing resin. Finishing and polishing of the mandibular overdenture containing the locator attachments caps were done prior to insertion of the prostheses ${ }^{10}$ (Fig. 5). On delivery, the lightweight overdenture presented satisfactory occlusion, good retention, and stability, and the

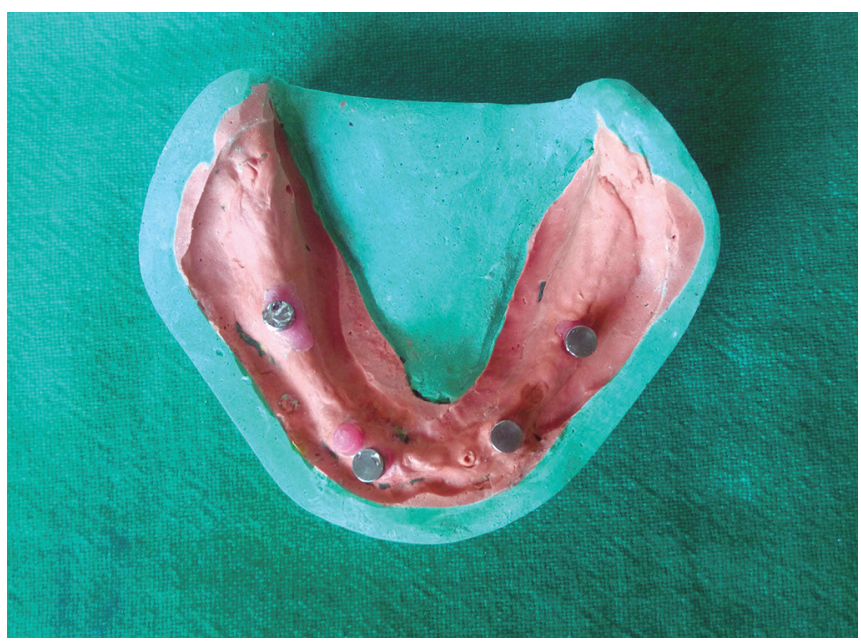

Fig. 4: Master model with locator abutments 


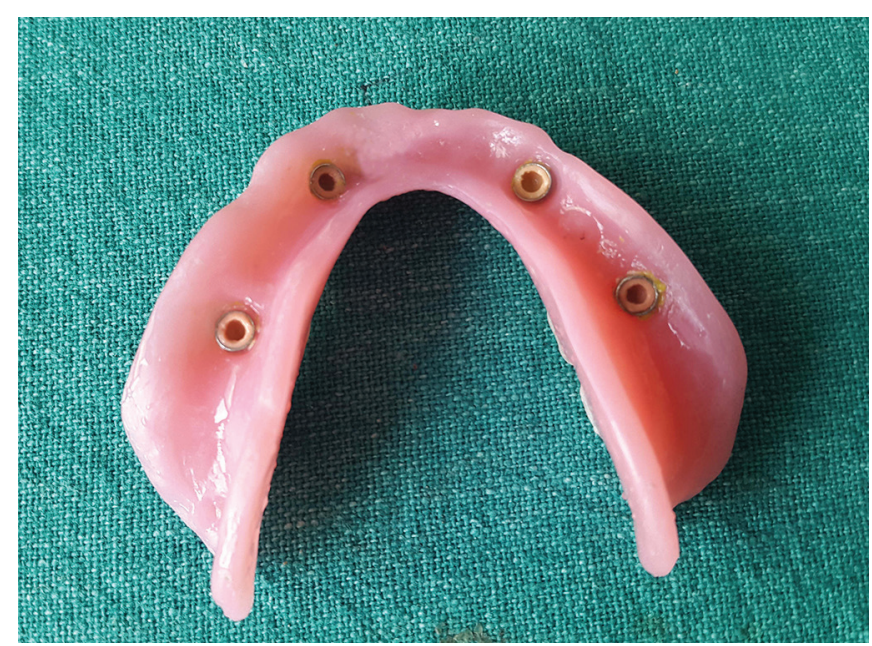

Fig. 5: Final overdenture with locator processing caps

patient reported a feeling of comfort and satisfaction of his demands (Fig. 6). Thorough hygiene instructions were given, and the patient was scheduled for periodic recall and maintenance.

\section{DISCUSSION}

The utilization of implants has significantly broadened the range of additional benefits that the prosthodontist can offer to the patient. ${ }^{11}$ The primary advantages of an implant-stabilized denture are the improved retention, significant reduction in denture movement during physiologic function, along with relatively attenuated loading of the oral mucosa. The action of the oral musculature as well as the tongue during various functions does not displace the removable implant-supported denture. ${ }^{12}$

Formulation of a definite treatment plan is a crucial step in order to ensure the successful fabrication of an implant-supported prosthesis. ${ }^{13}$ Therefore, thorough assessments, such as an elaborative documentation of the patient's medical, dental history, and radiographic evaluation must always be carried out. After a few weeks of use, the patient reported an appreciable increase in his ability to masticate. The enhanced chewing ability and force can be attributed to the increased, stable occlusal contact between the maxillary and mandibular dentures. ${ }^{14}$ Placement of four endosseous implants was not only structurally sufficient to adequately support and retain the mandibular denture, but was also economically viable for the patient.

\section{CONCLUSION}

Advancement in dentistry gives us opportunity to shift our treatment plan from conventional removable prosthodontics to implant-supported fixed prosthodontics, but sequence of tooth loss and the socioeconomic condition of the patient are few variables that force an alternative

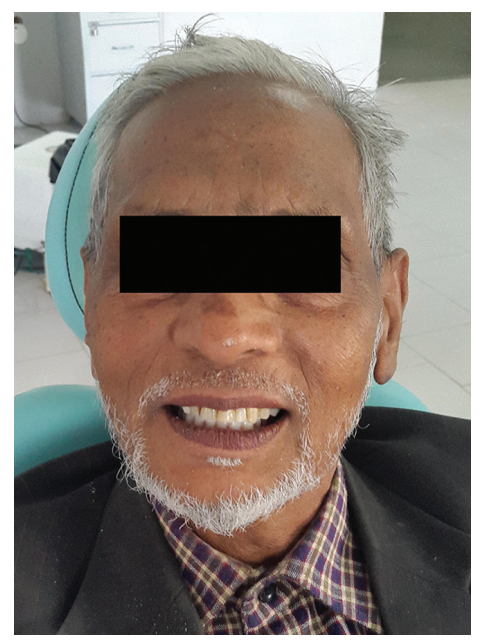

Fig. 6: Postoperative extraoral view

treatment plan. In the present case report, we have tried to restore the occlusion of a patient who was completely edentulous in the mandibular arch, by fabricating implant-supported mandibular overdenture opposing natural dentition in the maxillary arch.

\section{CLINICAL SIGNIFICANCE}

Although implant-supported fixed prosthesis is a better option to rehabilitate edentulous arches, satisfactory occlusion and mastication can also be restored with implant-supported overdenture opposing natural dentition.

\section{ACKNOWLEDGMENTS}

Authors would like to thank the management, faculty members, and the residents for their valuable support to carry out treatment of the cases in the department.

\section{REFERENCES}

1. Fiske J, Davis DM, Frances C, Gelbier S. The emotional effects of tooth loss in edentulous people. Br Dent J 1998 Jan;184(2): 90-93.

2. Humphris GM, Healey T, Howell RA, Cawood J. The psychological impact of implant-retained mandibular prostheses: a cross-sectional study. Int J Oral Maxillofac Implants 1995 Jul-Aug;10(4):437-444.

3. Awad MA, Lund JP, Shapiro SH, Locker D, Klemetti E, Chehade A, Savard A, Feine JS. Oral health status and treatment satisfaction with mandibular implant overdentures and conventional dentures: a randomized clinical trial in a senior population. Int J Prosthodont 2003 Jul-Aug;16(4):390-396.

4. Attard NJ, Zarb GA. Long-term treatment outcomes in edentulous patients with implant overdentures: the Toronto study. Int J Prosthodont 2004 Jul-Aug;17(4):425-433.

5. Jennings DE. Treatment of the mandibular compromised ridge: a literature review. J Prosthet Dent 1989 May;61(5): 575-579.

6. Feine JS, Carlsson GE, Awad MA, Chehade A, Duncan WJ, Gizani S, et al. The McGill Consensus Statement on 
Overdentures. Montreal, Quebec, Canada. May 24-25, 2002. Int J Prosthodont 2002;15:413-414.

7. Zitzmann NU, Marinello CP. A review of clinical and technical considerations for fixed and removable implant prostheses in the edentulous mandible. Int J Prosthodont 2002 JanFeb;15(1):65-72.

8. Besimo, C. Removable partial dentures on osseintegrated implants: principles of treatment planning and prosthetic rehabilitation in edentulous mandible. Chicago: Quintessence Publishing Co.; 1998.

9. Krennmair G, Weinländer M, Krainhöfner M, Piehslinger E. Implant-supported mandibular overdentures retained with ball or telescopic crown attachments: a 3-year prospective study. Int J Prosthodont 2006 Mar-Apr;19(2): 164-170.
10. Vogel R. Clinical technique to simplify overdenture success. Implant Realities 2006;1:19-20.

11. Mericske-Stern R. Treatment outcomes with implantsupported overdentures: clinical considerations. J Prosthet Dent 1998 Jan;79(1):66-73.

12. Feine, JS, Carlsson GE. Implant overdentures the standard of care for edentulous patients, New York, 2003, Quintessence.

13. Feine JS, Carlsson GE, Awad MA, Chehade A, Duncan WJ, Gizani S, Head T, Lund JP, MacEntee M, Mericske-Stern R, et al. The McGill Consensus Statement on Overdentures. Montreal, Quebec, Canada. May 24-25, 2002. Int J Prosthodont 2002 Jul-Aug;15(4):413-414.

14. Kim Y, Oh TJ, Misch CE, Wang H. Occlusal considerations in implant therapy: clinical guidelines with biomechanical rationale. Clin Oral Implants Res 2005 Feb;16(1):26-35. 